Journalof BANKING \&

FINANCE

\title{
Risk averse bank managers: Exogenous shocks, portfolio reallocations and market spillovers
}

\author{
Rowena A. Pecchenino ${ }^{1}$ \\ Department of Economics, Michigan State University, Marshall Hall, East Lansing, MI 48824-1038, \\ USA
}

Received 7 September 1996; accepted 2 October 1997

\begin{abstract}
This paper develops a model of the banking market in which individual banks make decisions concerning both the size and risk characteristics of their portfolios, and in which actions of one bank spill over to affect actions of other banks. Various observed banking market behaviors, such as herding, credit crunches, bank reaction to policy changes, etc., are explained as optimal bank responses to idiosyncratic or systemic shocks. (C) 1998 Elsevier Science B.V. All rights reserved.
\end{abstract}

JEL classification: G11; G21; G28

Keywords: Portfolio allocation; Spillovers; Credit crunch

\section{Introduction}

At the beginning of the 1990s credit conditions tightened, leading some to suggest that the US economy was being strangled by a credit crunch. This ostensible credit crunch led to a resurgence of academic and Federal Reserve interest in banking market phenomena, as typified by the work of Bernanke and

\footnotetext{
${ }^{1}$ Tel.: +1 517353 6621; fax: +1 517432 1068; e-mail: rowenap@msu.edu. 
Lown (1991), Owens and Schreft (1992), Friedman (1991), Green and Oh (1991), and Peek and Rosengren (1992). However, what many of these papers lack is a theoretical model that explains either the forces in the economy capable of generating fluctuations in bank portfolio choice behavior, or which of these forces can lead to a credit crunch.

In this paper I develop a model of the banking market in which bank managers are assumed to differ in their tolerance of risk, and to choose the size and risk characteristics of their investment portfolios optimally. Risk averse depositors allocate their funds among banks given their information about bank portfolio risk. The banks take into account the effects on their own return to lending and cost of borrowing of changing their portfolio size and risk, but ignore their effects on other banks and the market. However, their actions spill over to affect the actions of other banks.

I use the model to examine banks' portfolio reallocations induced by idiosyncratic or systemic shocks to their local or global market fundamentals or to their tolerance of risk. Specifically, in an asymmetric Nash equilibrium a positive shock to an individual bank's return to lending, such as hiring a more skillful manager, will cause that bank to expand its lending and decrease its portfolio risk; these changes in lending spill over onto the other banks and cause them to expand their lending and decrease their portfolio risk as well. In contrast, a positive shock to a bank's cost of borrowing, as a result, for example, of a competitor opening a new branch, has the opposite effect on the bank and the market.

Systemic shocks to banks' return to lending, such as an increase in competition from non-bank lenders or an increase in non-risk-based capital adequacy requirements, or costs of borrowing, such as an increase in competition for depositor's funds from non-bank banks or an increase in reserve requirements, have similar qualitative effects on the banking market. Further, if a single bank's tolerance for risk rises, then it increases both the size and the riskiness of its portfolio. The spillover effect of this action causes the other banks to increase the size but to decrease the risk of their portfolios. This behavior is consistent with localized credit crunches or booms. A systemic decrease in risk tolerance leads all banks to decrease portfolio size and risk. Depending on the source of the shock, for example sunspots or regulatory change, banks' optimal responses to the shock can lead to herd-like behavior or a credit crunch. Finally, a falling risk free rate of return leads to an expansion of credit accompanied by either an increase or decrease in portfolio risk. These predictions of the model are consistent with the stylized facts.

The paper proceeds as follows. In Section 2 the model is developed, and in Section 3 the theoretical results are derived. Section 4 uses the findings of the model to examine the recent "credit crunch" controversy. Section 5 concludes. 


\section{The model}

This model builds on the framework developed in Pecchenino (1992) and is a generalization of the analysis in Mondschean and Pecchenino (1995). Assume that there are two classes of agents: banks and depositors, and $N$ types of banks, $i=1, \ldots, N$, where type is a measure of managerial risk tolerance. The gross risk free rate of return on lending is $r \alpha(L)$, where $L$ measures aggregate loanable funds, and $r>0$ is a shift parameter. Thus an increase in $L$ represents a shift in the aggregate supply of loanable funds to the market, which will, in general, lead to a decrease in all interest rates, so $\alpha^{\prime}<0$. Depositors are risk averse.

There is one source of bank failure in this model: portfolio risk. Portfolio risk, indexed by $\sigma$, is chosen optimally by banks given their tolerances of risk and depositor behavior. Let $\pi(\sigma)$ be the probability that a bank holding a portfolio of risk $\sigma$ fails, where $\pi(\sigma) \in[0,1]$ for all $\sigma$. Assume that the probability of bank failure is increasing convex in bank risk: $\pi_{\sigma} \geqslant 0$ and $\pi_{\sigma \sigma} \geqslant 0$. This assumption follows the basic portfolio theory set out by Sharpe (1970). In his framework, expected returns increase with risk at a decreasing rate, so the probability of insufficient cash flows increases at an increasing rate. The $\pi($ ) function is common knowledge.

The empirical findings of Keeton and Morris (1987) suggest that bank managements differ in their preferences toward risk. I operationalize this difference as follows. Assume that a bank's preference toward risk can be summarized in a risk tolerance parameter, a parameter of its objective function. Specifically, let $\gamma_{i}$ be a type $i$ bank's risk tolerance parameter, where $\gamma_{i}<\gamma_{j}, i<j, \gamma_{i} \geqslant 1$, for all banks of type $i=1, \ldots, N$ : a type $j$ bank has a greater tolerance for risk than a type $i$ bank, $j>i$, and banks can be ranked by their tolerance of risk. The risk tolerance parameter enters a bank's objective function in the following way. Given a portfolio of risk $\sigma$ with probability of default $\pi(\sigma)$, a type $i$ bank evaluates whether this risk of default is worth taking at $\pi(\sigma) / \gamma_{i}$, while a type $j$ bank evaluates whether this risk of default is worth taking at $\pi(\sigma) / \gamma_{j}$. Since $\gamma_{j}>\gamma_{i}$, a type $j$ bank tolerates more risk than a type $i$ bank. While risk tolerance is a parameter, it is affected by, among other things, the local and global regulatory environment, extraneous uncertainty, and/or animal spirits, since all of these affect the actual or perceived benefit to risk-taking.

Two cases are examined. In Case 1 bank type, and thus bank portfolio risk, is common knowledge. In Case 2 depositors cannot distinguish among banks of different risk tolerances, but they know the distribution of risk tolerance, and thus portfolio risk.

In Case 1, risk-averse depositors, given the common knowledge of bank risk tolerances, allocate their funds among banks so that each dollar deposited in a bank with portfolio risk $\sigma$ earns the market determined risk adjusted return for bearing that level of risk. That is, the return per dollar deposited, $d^{1}$, in a bank with portfolio risk $\sigma$, with value $\hat{A}$ per dollar of deposits if insolvent is 


$$
[1-\pi(\sigma)] d^{1}+\pi(\sigma) \hat{A}=\rho(\sigma) r \alpha(L)
$$

where $r \alpha(L)$ is the gross risk free rate of return, defined above, and $\rho(\sigma)$ is the market premium for the risk of investing in a bank with portfolio risk $\sigma, \rho^{\prime}>0, \rho^{\prime \prime} \geqslant 0, \rho(\sigma)>1 \forall \sigma$. Thus

$$
d^{1}(\sigma, L ; r, \hat{A})=\frac{r \rho(\sigma) \alpha(L)-\pi(\sigma) \hat{A}}{[1-\pi(\sigma)]},
$$

where, if $\alpha(L)>\hat{A}, d_{\sigma}^{1}>0, d_{L}^{1}<0, d_{\sigma \sigma}^{1}>0, d_{\sigma L}^{1}<0, d_{r}^{1}>0, d_{r L}^{1}<0$, and $d_{\sigma r}^{1}>0$. Assume $\hat{A}=0$.

In Case 2, to risk averse depositors all banks are, ex ante, observationally equivalent. Assume depositors know the distribution of managerial risk preferences, and thus the distribution of portfolio risk. Then it is optimal for depositors to divide their funds equally among all banks and demand a return per dollar invested, $d^{2}$, that satisfies

$$
\int_{\hat{0}}^{\bar{\sigma}}\left[\left(1-\pi\left(\sigma_{i}\right)\right) d^{2}+\pi\left(\sigma_{i}\right) \hat{A}\right] \mathrm{d} \sigma=\int_{0}^{\bar{\sigma}} \rho\left(\sigma_{i}\right) r \alpha(L) \mathrm{d} \sigma,
$$

where portfolio risk is distributed on the support $[0, \bar{\sigma}]$, all other functions are as defined above. Then

$$
d^{2}(\tilde{\sigma}, L ; r, \hat{A})=\frac{r \rho(\tilde{\sigma}) \alpha(L)-\pi(\tilde{\sigma}) \hat{A}}{[1-\pi(\tilde{\sigma})]},
$$

where $\tilde{\sigma}$ is mean portfolio risk, so $\rho(\tilde{\sigma})$ is the average risk premium and $\pi(\tilde{\sigma})$ is the average probability of bankruptcy. Notice that the return per dollar invested in bank $i$ does not depend on the riskiness of bank $i$ 's portfolio. Then, if $\alpha(L)>\hat{A}, d_{\sigma_{i}}^{2}=0$ but $d_{\tilde{\sigma}}^{2}>0, d_{L}^{2}<0, d_{\tilde{\sigma} \tilde{\sigma}}^{2}>0, d_{\tilde{\sigma} L}^{2}<0, d_{r}^{2}>0, d_{r L}^{2}<0$, and $d_{\tilde{\sigma} r}^{2}>0$. Assume, as before, $\hat{A}=0$.

Banks, in both Cases 1 and 2, are assumed to be small relative to the market so that they take the effects of their lending on market returns to be infinitesimal. However, assume that portfolio returns, adjusted for risk, are declining in aggregate lending, also measured by $L=\Sigma_{i} \ell_{i}$, where $\ell_{i}$ is bank $i$ 's loanable funds. Then, conditional on solvency, the market value of bank $i$ 's asset portfolio with risk $\sigma_{i}$, per dollar of deposits, is $A^{i}\left(\sigma_{i}, L ; \theta_{i}^{A}\right), A_{\sigma}>0, A_{\sigma \sigma} \leqslant 0$, $A_{L}<0, A_{\sigma L}=0$, where $\theta_{i}^{A}$ is a shock to bank $i$ 's asset value function; assume $A_{\theta^{4}}>0, A_{\sigma \theta^{4}}>0$. The asset portfolio production function is bank specific, and can vary across banks as a result of differences in individual bank managements' skill at information gathering, etc. The shock to the asset function can take on either an idiosyncratic or a systemic interpretation. If $\theta_{i}^{A} \neq 0$ and $\theta_{j}^{A}=0$ for all $j \neq i$, then the shock represents a change in the fundamentals of the bank's local market, other local markets' fundamentals unchanged. If 
$\theta_{i}^{A}=\theta_{j}^{A}$ for all $i, j$, then the shock represents a change in global market conditions. $^{2}$

The market value of its liabilities per dollar of deposits (loanable funds, $\ell_{i}$ ) are determined by both direct and indirect deposit costs. Then, in Case 1 the market value of a type $i$ bank's liabilities per dollar of deposits is $D^{1 i}\left(\sigma_{i}, L, \ell_{i}, r, \theta_{i}^{D}\right)=\left\{d^{1}\left(\sigma_{i}, L ; r, \theta_{i}^{D}\right)+c\left(\ell_{i}, L, \theta_{i}^{D}\right)\right\}$ where $d^{1}()$ is the interest cost per dollar and $c\left(\right.$ ) is the cost of raising funds (attracting deposits), ${ }^{3}$ where $c_{\ell}>0, c_{\ell \ell}>0, c_{L}<0 ; \theta_{i}^{D}$ is a shock to bank $i$ 's liabilities value function. This shock can also take on either an idiosyncratic or a systemic interpretation. If $\theta_{i}^{D} \neq 0$ and $\theta_{j}^{D}=0$ for all $j \neq i$, then the shock represents a change in the fundamentals of the bank's local market, other local markets' fundamentals unchanged. If $\theta_{i}^{D}=\theta_{j}^{D}$ for all $i, j$, then the shock represents a change in global market conditions. ${ }^{4}$ Thus, $D_{\sigma}^{1}>0, D_{\sigma \sigma}^{1}>0, D_{\ell}^{1}>0, D_{\ell \ell}^{1}>0, D_{\sigma \ell}^{1}=0$, $D_{L}^{1}<0, D_{\sigma L}^{1}<0, D_{\ell L}^{1}=0, D_{r}^{1}>0, D_{\sigma r}^{1}>0, D_{\ell r}^{1}=0$, and assume $D_{\theta^{D}}^{1}>0$, $D_{\sigma \theta^{D}}^{1}>0$, and $D_{\ell \theta^{D}}^{1} \geqslant 0$.

The market value of a type $i$ bank's liabilities in Case 2 is $D^{2 i}\left(\tilde{\sigma}, L, \ell_{i}, r, \theta_{i}^{D}\right)=$ $\left\{d^{2}\left(\tilde{\sigma}, L ; r, \theta_{i}^{D}\right)+c\left(\ell_{i}, L, \theta_{i}^{D}\right)\right\}$ where $d^{2}()$ is the interest cost per dollar of deposits, all else is as defined above. Thus, $D_{\sigma_{i}}^{1}=0$ but $D_{\tilde{\sigma}}^{2}>0, D_{\tilde{\sigma} \tilde{\sigma}}^{2}>0$, $D_{\ell}^{2}>0, D_{\ell \ell}^{2}>0, D_{\tilde{\sigma} \ell}^{2}=0, D_{L}^{2}<0, D_{\tilde{\sigma} L}^{2}<0, D_{\ell L}^{2}=0, D_{r}^{1}>0, D_{\tilde{\sigma} r}^{2}>0, D_{\ell r}^{2}=$ 0 , and assume $D_{\theta^{D}}^{2}>0, D_{\tilde{\sigma} \theta^{D}}^{2}>0$, and $D_{\ell \theta^{D}}^{2} \geqslant 0$.

In both Cases 1 and 2 if a bank fails (the market value of its assets is less than the market value of its liabilities) it is immediately closed (by statute). Since a bank's assets are assumed to be worthless in the event of failure, bank depositors' absorb the loss.

The type $i$ bank, taking all other banks' lending and portfolio risk decisions as given, and considering itself small relative to the market, chooses $\sigma_{i}$, its portfolio risk, and $\ell_{i}$, its portfolio size, to maximize

$$
\max \left[1-\frac{\pi\left(\sigma_{i}\right)}{\gamma_{i}}\right]\left[A^{i}\left(\sigma_{i}, L ; \theta_{i}^{A}\right)-D^{i}\left(\sigma_{i}, L, \ell_{i} ; r, \theta_{i}^{D}\right)\right] \ell_{i},
$$

where $\pi\left(\sigma_{i}\right) / \gamma_{i}$ is the probability of bankruptcy weighted by the bank's risk tolerance. The first-order conditions are

\footnotetext{
${ }^{2}$ For example, a large company opens (closes) a plant in bank $i$ 's market. While this improves local market conditions, it does not affect global conditions. However, if the economy goes into a recession, global market fundamentals worsen.

${ }^{3}$ These indirect costs could be the advertising costs required to attract new depositors, the cost of opening a new branch to better serve existing customers, the cost of borrowing overnight funds to meet short-term lending needs, etc. These costs fall when total available funds rise.

${ }^{4}$ For example, bank $j$ may enter bank $i$ 's market thereby increasing local competition while leaving global conditions unchanged. Or, substitutes for bank deposit accounts are introduced, increasing competition among banks and non-banks in the global market, driving up deposit costs for all banks.
} 


$$
\begin{aligned}
& -\frac{\pi^{\prime}}{\gamma_{i}}\left[A^{i}()-D^{i}()\right]+\left[1-\frac{\pi()}{\gamma_{i}}\right]\left[A_{\sigma}^{i}-D_{\sigma}^{i}\right]=0, \\
& {\left[A^{i}()-D^{i}()\right]-D_{\ell}^{i} \ell=0 .}
\end{aligned}
$$

The second-order conditions are satisfied since

$$
\begin{aligned}
& \Delta= \\
& \operatorname{det}\left[\begin{array}{ll}
-\frac{\pi^{\prime \prime}}{\gamma_{i}}\left[A^{i}-D^{i}\right]-\frac{2 \pi^{\prime}}{\gamma_{i}}\left[A_{\sigma}^{i}-D_{\sigma}^{i}\right]+\left[1-\frac{\pi}{\gamma_{i}}\right]\left[A_{\sigma \sigma}^{i}-D_{\sigma \sigma}^{i}\right] & \frac{\pi^{\prime}}{\gamma_{i}} D_{\ell}^{i} \\
{\left[A_{\sigma}^{i}-D_{\sigma}^{i}\right]} & -2 D_{\ell}^{i}-D_{\ell \ell}^{i} \ell
\end{array}\right] \\
& >0 .
\end{aligned}
$$

Eqs. (2) and (3) together define bank $i$ 's reaction function. These first- and second-order conditions hold for both Cases 1 and 2, where, in Case 2, $D_{\sigma}=0$ and $D_{\sigma \sigma}=0$.

A Nash equilibrium is defined by the sequence of pairs $\left\{\left(\sigma_{i}^{*}, \ell_{i}^{*}\right),\left(\sigma_{-i}^{*}, \ell_{-i}^{*}\right)\right\} \forall i$, where $\left(\sigma_{i}^{*}, \ell_{i}^{*}\right)$ is the optimal response of bank $i$ to all other banks choices $\left(\sigma_{-i}^{*}, \ell_{-i}^{*}\right)$.

\section{Comparative static results}

To derive the effects of idiosyncratic changes in one bank's behavior on other banks, and of systemic shocks, I examine the case where there are only two types of banks, which are assumed to differ in risk tolerances, and, potentially, to have different portfolio choice options as well as different costs of funds. Assume there are $k$ banks of type 1 and $K+1-k$ banks of type 2 . Without loss of generality assume $k=1$. In this case the equilibrium is defined by the simultaneous solution of the first-order conditions of the two types of banks' maximization problems:

$$
\begin{aligned}
& -\frac{\pi^{\prime}}{\gamma_{1}}\left[A^{1}()-D^{1}()\right]+\left[1-\frac{\pi()}{\gamma_{1}}\right]\left[A_{\sigma_{1}}^{1}-D_{\sigma_{1}}^{1}\right]=0, \\
& {\left[A^{1}()-D^{1}()\right]-D_{\ell_{1}}^{1} \ell_{1}=0,} \\
& -\frac{\pi^{\prime}}{\gamma_{2}}\left[A^{2}()-D^{2}()\right]+\left[1-\frac{\pi()}{\gamma_{2}}\right]\left[A_{\sigma_{2}}^{2}-D_{\sigma_{2}}^{2}\right]=0, \\
& {\left[A^{2}()-D^{2}()\right]-D_{\ell_{2}}^{2} \ell_{2}=0 .}
\end{aligned}
$$

To determine the effect of changes in exogenous variables on banks portfolio choice behavior, totally differentiate Eqs. (5)-(8), taking account of the fact that $L=\ell_{1}+K \ell_{2}$. For Case 1 this yields 


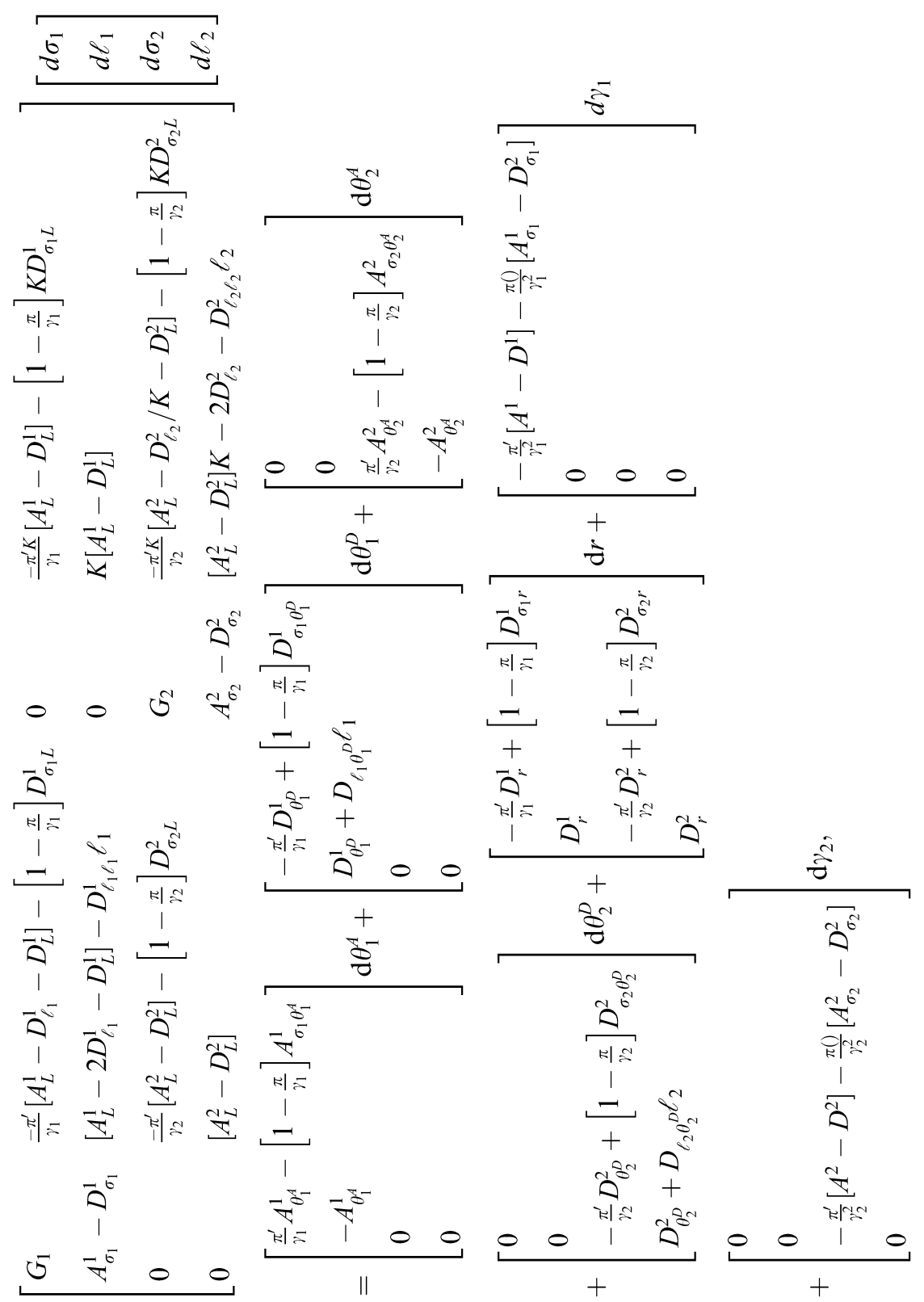


where $G_{i}=-\frac{\pi^{\prime \prime}}{\gamma_{i}}\left[A^{i}-D^{i}\right]-\frac{2 \pi^{\prime}}{\gamma_{i}}\left[A_{\sigma}^{i}-D_{\sigma}^{i}\right]+\left[1-\frac{\pi}{\gamma_{j}}\left[A_{\sigma \sigma}^{i}-D_{\sigma \sigma}^{i}\right]<0, i=1,2\right.$. In Case 2 the right-hand side of the equation is the same, but the zero entries in the left-hand side matrix are now non-zero, and equal (from top to bottom) $\pi^{\prime} D_{\tilde{\sigma}}^{1} / \gamma_{1},-D_{\tilde{\sigma}}^{1}, \pi^{\prime} D_{\tilde{\sigma}}^{2} / \gamma_{2},-D_{\tilde{\sigma}}^{2}$, respectively.

Sufficient for the determinant of the left-hand side matrix to be positive is that

(i) $A_{L}^{i}-D_{L}^{i}>0, i, j=1,2$,

(ii) $\frac{-\pi^{\prime}}{\gamma_{i}}\left[A_{L}^{i}-D_{L}^{i}\right]-\left[1-\frac{\pi}{\gamma_{i}}\right] D_{\sigma_{i} L}^{i}<0 i, j=1,2$,

(iii) $\left[A_{L}^{1}-2 D_{\ell_{1}}^{1}-D_{L}^{1}-D_{\ell_{1} \ell_{1} \ell_{1}}^{1}\right]<0,\left[K\left(A_{L}^{2}-D_{L}^{2}\right)-2 D_{\ell_{2}}^{2}-D_{\ell_{2} \ell_{2} \ell_{2}}^{2}\right]<0$,

(iv) $\left[A_{L}^{1}-2 D_{\ell_{1}}^{1}-D_{L}^{1}-D_{\ell_{1} \ell_{1}}^{1} \ell_{1}\right]\left[K\left(A_{L}^{2}-D_{L}^{2}\right)-2 D_{\ell_{2}}^{2}-D_{\ell_{2} \ell_{2}}^{2} \ell_{2}\right]-K\left(A_{L}^{1}-D_{L}^{1}\right)$

$\left(A_{L}^{2}-D_{L}^{2}\right)>0$,

(v) $D_{\ell,}^{i}$ small; $i=1,2$

and, for Case 2

(vi) $D_{\tilde{\sigma}}^{i}$ small, $i=1,2$.

The conditions can be interpreted as follows. Under condition (i) an increase in aggregate lending reduces the cost of funds faced by a bank more than it reduces the returns to lending. Under condition (ii) the indirect effect of an increase in aggregate lending reduces the marginal value of the portfolio. This increase in lending is equivalent to an increase in competition among banks for the same lending opportunities, which enables borrowers to demand and get better terms on their loans, given risk. Condition (iii) requires that the return to portfolio expansion be decreasing at the margin. Under condition (iv) the direct effects of a change in portfolio size outweigh the indirect effects at the margin. Finally, condition (v) requires that the marginal cost of expanding lending not be too high, while condition (vi) requires that the marginal cost of increasing aggregate portfolio risk be small. ${ }^{5}$

Evaluating these derivatives under the above conditions, yields the following results for both Cases 1 and 2 .

\footnotetext{
${ }^{5}$ An examination of the data on returns on other checkable deposits and 90-day Treasury bills from the Division of Monetary Affairs of the Board of Governors of the Federal Reserve System show that the last condition is consistent with stylized fact. First, the variance of the return on other checkable deposits, measured monthly from March 1970 to November 1996, is only 17.5\% of the variance of 90-day Treasury bills over the same period, and the correlation between the interest rate on 90-day Treasury bills and the interest rate spread between Treasury bills and other checkable deposits is 0.91 . Both these statistics suggest that interest rates on deposits vary very little over time, and so very little in response to changes in average portfolio risk. Second, examination of the time series of rates on other checkable deposits shows very little month to month variation over long periods.
} 
Proposition 1. Assume

$$
\frac{\pi^{\prime}}{\gamma_{i}} A_{\theta_{i}^{4}}^{i}-\left[1-\frac{\pi}{\gamma_{i}}\right] A_{\sigma_{i} \theta_{i}^{4}}^{i}>0, i=1,2 .
$$

Then a positive shock to bank 1's andlor the K bank 2's asset function( $s$ ) leads both types of banks to expand lending and reduce portfolio risk.

A positive idiosyncratic shock to one bank's asset value function, such as a new more skillful loan officer with the same risk tolerance being hired, causes that lender to expand lending and reduce its risk exposure. The increase in local lending increases aggregate lending, and through this channel lenders in other localities with unchanged fundamentals will find it individually optimal both to expand their lending, since the net return on their portfolios has increased at the margin, and to reduce their risk exposure, since the return to risk-taking has decreased at the margin. Thus, an improvement in one market spills over onto the global market: a multiplier effect occurs. ${ }^{6}$

A positive systemic shock to all banks asset value functions also causes an expansion in lending and a reduction in portfolio risk. Examples of such systemic shocks include increased competition from non-bank lenders, and a reduction in borrower creditworthiness as a result of a cyclical downturn. Both negative shocks reduce banks' returns at all levels of risk, and so lead to a contraction of credit and an increase in risk, since the return to risk-taking has increased on the margin. A tightening of capital adequacy requirements that reduced returns at each level of risk could also be an example of a systemic shock in this framework. The higher capital adequacy requirement, counterintuitively, would lead to higher bank risk as banks would take on greater risk to maintain their portfolio returns. This suggests that capital adequacy requirements not linked to portfolio risk could have the opposite of the intended effect, as has been the case historically.

Proposition 2. Assume

$$
-\frac{\pi^{\prime}}{\gamma_{i}} D_{\theta_{i}^{D}}^{i}+\left[1-\frac{\pi}{\gamma_{i}}\right] D_{\sigma_{i} \theta_{i}^{D}}^{i}<0 .
$$

Then a positive shock to bank l's andlor to the K bank 2's deposit value function $(s)$ (the banks' cost of deposits) leads both types of banks to contract lending and increase portfolio risk.

\footnotetext{
${ }^{6}$ The feature of the bank's value (objective) function that is necessary for this spillover/multiplier effect to be possible is that the marginal return to lending increases when other banks increase their lending: there is a strategic complementarity (see Cooper and John, 1988). The banks' objective functions have this feature. Thus, when one bank chooses to lend more (less), for whatever reason, all other banks find it in their interest to follow suit.
} 
A positive idiosyncratic shock to a bank's deposit costs, such as those caused by the opening of a branch by a competitor bank, causes it to seek farther afield for deposits. This increases competition for deposits in other markets, driving up other banks' costs as well. To maintain their portfolio, these banks would have to raise funds outside their local market, but the increase in costs induces a reduction in lending and an increase in risk to cover the higher costs. Worsening conditions in one market have negative systemic effects.

A positive systemic shock to banks' deposit cost functions generates a reduction in lending and an increase in portfolio risk. For example, if competition from non-bank banks for depositors' funds increased, all banks would see their cost of funds rise, and their access to funds fall. In response, banks would be forced to invest in riskier assets to cover their costs, and at the same time reduce overall lending. A reduction in reserve requirements would have the opposite effect on bank behavior if the reserve requirements had been imposing a binding constraint on bank lending prior to the regulatory change.

The first two propositions concern changes in local or global market fundamentals. The third concerns bank characteristics.

Proposition 3. An increase in bank 1's (the K bank 2's) risk tolerance (s) causes bank 1 (the $K$ bank $2 s$ ) to expand lending and increase portfolio risk, and the $K$ bank $2 s$ (bank 1) to expand lending but decrease portfolio risk. If both types of banks' risk tolerances increase, then both will expand lending and increase portfolio risk if own effects exceed cross effects.

When a bank becomes more tolerant of risk, it behaves profligately increasing lending and lending to more risky ventures. Other banks are drawn into the fray because the increase in aggregate lending increases their returns on the margin, but their lending is directed to less risky borrowers because the same increase in aggregate lending has reduced returns to risk-taking. This result is consistent with the recent real estate booms in New England and on the West Coast. While lending expanded nationwide, increased risk taking was concentrated in two local markets.

The conclusion that can be drawn from this proposition is that a systemic shock to banks' risk tolerances, for example because of animal spirits of the Howitt and McAfee (1992) variety, or as a result of sunspots of Azariadis (1981), or because of a regulatory change that affects the return to risk-taking such as the Basel Accord, leads all banks to increase (decrease) portfolio risk and size. Such behavior is consistent with a herd in which a bank's portfolio choice behavior is consistent with other banks' portfolio choice behavior, but is inconsistent with market fundamentals. This type of behavior is described by Keynes (1936), examined by Scharfstein and Stein (1990) and Banerjee (1992), and is consistent with the firm behavior suggested by the management market signaling/reputation maintenance model of Rajan (1994). 
Monetary policy or a change in market fundamentals can, in the framework of this model, be represented by a shift of the deposit supply function as a result of a reduction of the risk free rate of return. Banks see this as a reduction in their cost of funds, at all levels of portfolio risk. Banks' responses are summarized in Proposition 4.

Proposition 4. A decrease in the risk free rate of return causes both types of banks to expand lending and either increase or decrease portfolio risk.

This result is consistent with Sharpe's analysis of portfolio choice behavior (Sharpe, 1970) since a reduction in the risk free rate lowers banks' costs of funds, which encourages lending, but more lending reduces the return to lending at a given level of risk. So, whether risk rises or falls depends on an individual bank's risk tolerance.

\section{The recent credit crunch - An interpretation}

Much of the examination of credit availability in the early 1990s has been directed at determining whether a credit crunch occurred and if so was there a policy response available to the Federal Reserve. A credit crunch is variously defined (see Owens and Schreft, 1992, for a comparison of credit crunch definitions), but what is generally agreed is that the supply of lending falls, and this reduction can be accomplished via a reduction in lending at all levels of risk (Bernanke and Lown, 1991; Berger and Udell, 1994; Wojnilower, 1992) and/ or by a tightening of non-price loan terms at all levels of risk (Owens and Schreft, 1992; Friedman, 1991; Berger and Udell, 1994; Wojnilower, 1992; Cantor and Wenninger, 1993).

The model developed here suggests three potential sources of a credit crunch: a negative idiosyncratic shock to a single bank's asset value function (Proposition 1), a negative systemic shock to all banks' asset value functions (Proposition 1), or a negative systemic shock to all banks' tolerances of risk (Proposition 3). The first two sources suggest that a credit crunch would be typified by a tightening of credit accompanied by an increase in portfolio risk, which appears to be inconsistent with banks accomplishing the reduction of credit via a tightening of non-price loan terms. The third source suggests that a credit crunch would be typified by a tightening of credit accompanied by a reduction in bank risk.

If a credit crunch is the result of a change in market fundamentals, as it would be if it resulted from an idiosyncratic or systemic shock to the asset value function (Proposition 1), then the Federal Reserve's policy response would need also to act on asset market fundamentals. It is not immediately obvious that such a policy option exists. 
If a credit crunch is the result of pervasive pessimism in the banking market, or of extraneous uncertainty, then the Federal Reserve may have a greater role, to the extent that it can affect banks' perceptions of the market. Suppose, for example, that banks' market outlook depends, in part, on their perceptions of examiner strictness. If all banks believe that examiners are going to be more strict, then pessimism may pervade the market, leading to a credit crunch. This result is, indirectly, consistent with Darin and Walter (1994). They examine whether examiners were indeed too strict with the troubled banks in New England and in California in the early 1990s. They find that examiners were not too strict. But, the quotes from the American Banker with which they open their paper strongly suggest that banks did perceive, perhaps contrary to reality, excessive strictness on the part of bank examiners.

Now suppose the relative returns on high risk assets are reduced via the imposition of higher risk-based capital adequacy requirements. Holding constant the asset composition of a portfolio, the regulations reduce a bank's willingness to take on this portfolio risk. Thus, all banks' tolerances of risk fall, and all banks reduce portfolio risk and size, all else equal. Thus, this change in prudential regulation could have the side effect of inducing a credit crunch. This result is consistent with the findings of Peek and Rosengren $(1995,1992)$ for the New England region in the late 1980s and early 1990s, Hancock et al. (1995), and is partially consistent with the findings of Haubrich and Wachtel (1993) for the entire US. Haubrich and Wachtel, however, found that while banks did reduce their portfolio risk, they did not reduce their portfolio size, perhaps because risk free rates were falling over the period of their study.

\section{Conclusion}

In this paper a simple model of the banking market is developed to analyze the effects of sectoral and systemic shocks on individual bank and banking market behavior. In this model all banks are linked via the aggregate quantity of loanable funds. The effect of a shock to one bank's cost of funds or return to lending is not confined to that bank but spills over and affects other banks as well. Sectoral shocks can thus have global repercussions, and global shocks are intensified by the spillover effects. None of these results rely on depositors' level of knowledge concerning a banks' riskiness.

Many banking market events can be explained within the context of this simple model of bank behavior. Examples include: (i) the credit crunch of the early 1990s which can be interpreted as a response to the Basel Accord since the more stringent capital adequacy requirements simultaneously reduced all banks' tolerance of risk; (ii) the real estate lending booms in New England and on the West Coast which can be seen as localized shocks to risk tolerance in these two regions that spilled over onto the rest of the country; and (iii) 
banks' response to competition from non-banks and the commercial paper market which fits with systemic shocks either to banks asset and/or deposit value functions. But, since the model is static, it cannot explain the behavior of the banking market as these events unfold. This remains a topic for future research.

\section{Acknowledgements}

I am grateful for the hospitality of the International Centre for Economic Research, Turin, Italy, where much of this work was completed. I would also like to thank Donald Hester, Thomas Mondschean, Allen Berger, and Robert Rasche and two anonymous referees for their helpful comments. All remaining errors are mine alone.

\section{References}

Azariadis, C., 1981. Self-fulfilling prophecies. Journal of Economic Theory 25, 380-396.

Banerjee, A., 1992. A simple model of herd behavior. Quarterly Journal of Economics 107, 797819.

Berger, A., Udell, G., 1994. Did risk-based capital allocate bank credit and cause a "credit crunch" in the United States? Journal of Money, Credit and Banking 26, 585-628.

Bernanke, B., Lown, C., 1991. The credit crunch. Brookings Papers on Economic Activity, pp. 205-239.

Cantor, R., Wenninger, J., 1993. Perspective on the credit slowdown. Federal Reserve Bank of New York Quarterly Review 18, 3-36.

Cooper, R., John, A., 1988. Coordinating coordination failures in Keynesian models. Quarterly Journal of Economics 103, 441-464.

Darin, R., Walter, J., 1994. Were bank examiners too strict with New England and California banks. Federal Reserve Bank of Richmond Quarterly Review 80, 25-48.

Friedman, B., 1991. Comment on 'credit crunch'. Brookings Papers on Economic Activity, pp. $240-244$.

Green, E., Oh, S., 1991. Can a 'credit crunch' be efficient? Federal Reserve Bank of Minneapolis Quarterly Review 15, 3-17.

Hancock, D., Laing, A., Wilcox, J., 1995. Bank capital shocks: Dynamic effects on securities, loans, and capital. Journal of Banking and Finance 19, 661-677.

Haubrich, J., Wachtel, P., 1993. Capital requirements and shifts in commercial bank portfolios. Federal Reserve Bank of Cleveland Economic Review 29, 2-15.

Howitt, P., McAfee, R.P., 1992. Animal spirits. American Economic Review 82, 493-507.

Keeton, W., Morris, C., 1987. Why do banks' loan losses differ? Federal Reserve Bank of Kansas City Economic Review 72, 3-21.

Keynes, J.M., 1936. The General Theory of Employment, Interest and Money. Macmillan, Basingstoke, UK.

Mondschean, T., Pecchenino, R., 1995. Herd behavior or animal spirits: A possible explanation of credit crunches and bubbles. In: A. Cottrell, M. Lawlor, J. Wood (Eds.), The Causes and Costs of Depository Institution Failures. Kluwer Academic Publishers, Dordrecht, pp. 233-245. 
Owens, R., Schreft, S., 1992. Identifying credit crunches. Federal Reserve Bank of Richmond, Working paper 92.

Pecchenino, R., 1992. Risk-based deposit insurance: An incentive compatible plan. Journal of Money, Credit and Banking 24, 499-510.

Peek, J., Rosengren, E., 1992. The capital crunch in New England. New England Economic Review 21-31.

Peek, J., Rosengren, E., 1995. Bank regulation and the credit crunch. Journal of Banking and Finance 19, 679-692.

Rajan, R., 1994. Why bank credit policies fluctuate: A theory and some evidence. Quarterly Journal of Economics 399-442.

Scharfstein, D., Stein, J., 1990. Herd behavior and investment. American Economic Review 80, $465-479$.

Sharpe, W., 1970. Portfolio Theory and Capital Markets. McGraw-Hill, New York.

Wojnilower, A., 1992. Credit crunch. In: P. Newman, M. Milgate, J. Eatwell (Eds.), The New Palgrave Dictionary Of Money and Finance, vol. 1. Macmillan, Basingstoke, UK, pp. 525-526. 